\title{
How DEWA Increased Efficiencies and Value by Using Streamlined Project Management Processes
}

\author{
Tarek Hassan Tawfik - PMP, PMI - Case Study, Omran Al-Shamsi
}

\begin{abstract}
This study will presents the factors to achieve project management success; In terms of standards and methodology the organizations should adopt to achieve the values and benefits of project management. Multi-dimensional frameworks are validated and used in this study to measure project management performance and project success.

Dubai Electricity and Water Authority (DEWA) delivers worldclass services of electricity and water that meet the highest standards of availability, reliability and efficiency. DEWA serves over 842,000 customers across Dubai, a flourishing global city considered a leading hub of business activity in the Middle East and Northern Africa regions. Since its merger in 1992 of the Dubai Electricity Company and Dubai Water Department, DEWA has evolved and grown, measuring and adjusting the ways it serves its customers and integrating project management across the organization.

Dubai has experienced an unprecedented growth over the last two decades that transformed the city and propelled its gradual rise to global business prominence. This growth added complexity to the already daunting task of providing water and electricity services to consumers and businesses in a region with a population that exceeds two million. In 2014 alone, water connections increased nearly 30 percent, rising from 23,350 in 2013 to 30,000. The power demand increased another five to six percent in 2015. (DEWA Annual Statistics).

DEWA's leadership knows that adhering to proven project, program, and portfolio management practices reduces risks, cuts costs, and improves success rates. Top champion organizations realize the right project, program, and portfolio management practices give them a competitive edge. But there's always more that can —and should—be done. For the past six years, we have been conducting additional research to determine which factors have the most impact on project success. Based on a rigorous statistical analysis, three things rise to the top when it comes to helping organizations save millions of dollars: drivers of project success: (PMI pulse of profession - 2018)

1. Investing in actively engaged executive sponsors

2. Avoiding scope creep or uncontrolled changes to a project's scope

3. Maturing value delivery capabilities
\end{abstract}

\section{Introduction \& Background:}

Dubai has experienced an unprecedented growth over the last two decades that transformed the city and propelled its gradual rise to global business prominence. This growth added complexity to the already daunting task of providing water and electricity services to consumers and businesses in a region with a population that exceeds two million. In 2014 alone, water connections increased nearly 30 percent, rising from 23,350 in 2013 to 30,000. The power demand increased. 
"To keep pace with this growing demand for water and electricity services, the advent of green technologies and the push toward renewable energy, DEWA strives to achieve the leadership vision which was translated into the federal and local strategies. These include the UAE Centennial 2071, the UAE Vision 2021, the Dubai Plan 2021, and the Dubai Clean Energy Strategy 2050, ensuring the sustainable development of Dubai, to make it the happiest and smartest city in the

world," said His Excellency Saeed Mohammed Al Tayer, Managing Director and CEO of DEWA. As more and more projects were initiated, DEWA's leadership discovered that standard project management practices were not being observed across the organization, leading to decreased efficiencies, tempered innovation, redundant data, and an increased administrative burden on employees. At the time, DEWA relied on its 40 employed PMI certification holders to reinforce project management good practices. The number of certification holders continues to grow. DEWA now employs 60 PMI certification holders. DEWA's leadership knows that adhering to proven project, program, and portfolio management practices reduces risks, cuts costs, and improves success rates.

Because project ideas and strategies must be linked with data, workflow, and business processes, and because the complexity within projects is increasing, DEWA needed a way to measure, integrate, and streamline its project processes and ensure consistent practices organization wide.

Companies develop methodology to provide some degree of consistency in the way that some projects are managed. These types of methodology are often based upon rigid policies and procedures but can be successful.

\section{Good Methodology allow us to:}

1- Shorten project Schedule.

2- Reduce and/or better control cost.

3- Prevent unwanted scope changes.

4- Plan for better execution.

5- Predict results.

6- Improve customer relationship during execution.

7- Provide senior management with better visibility of status.

8- Standardize Execution.

9- Capture best practices.

Successful development and implementation of project management methodology requires:

1- Identification of the most common reasons for change in project management.

2- Identification of the ways to overcome the resistance to change.

3- Application of the principals of organizational change management to ensure that the desired project management environment will be created and sustained.

Methodologies do not manage projects: People do. It is the corporate culture that executes the methodology. If this done successfully, then the following benefits can be expected:

1- Better control of project scope.

2- Lower overall project risk.

3- Better decision-making process.

4- Greater customer satisfaction, which leads to increased business.

5- More time available for value-added efforts, rather than internal politics. 
Project management cannot succeed unless the project manager is willing to employ the system approach to project management by analyzing those variables that lead to success and failure:

1- Predicting project success.

2- Project Management Effectiveness.

3- Expectations.

4- Lesson Learned.

5- Best Practices.

Our organization and Throughout its strategic journey to realize its vision as a sustainable innovative world class utility, DEWA continues to develop and adopt methodologies that enables it to align with the UAE leadership ambitions and national plans, ensures stakeholders happiness, successful transition towards smart Dubai and excel! in the provisioning of electricity and water services. Therefore, DEWA recognizes the importance of having a strategy execution framework and methodologies that utilize portfolio, program, and project management as organizationalenabling practices to consistently optimize resources and time that leads to improved services, value to stakeholders and better social, economic and environmental results. The world's population is having a major impact on the Earth's environment, including the reduction of natural resources, and an increase in carbon emissions. This is the result of a number of factors including the current unsustainable lifestyle of the world's population. In addition, we are working in DEWA to achieve and support Dubai's Demand Side Management Strategy, to reduce energy and water demand by 30\% by 2030, and the Dubai Carbon Abatement Strategy to reduce carbon emissions by $16 \%$ by 2021 .

DEWA developed a unified project management approach based on benchmarking of best practices (PMI ${ }$, PRINCE2P ${ }^{\circledR}$ and ISO 21500 Guidance) to provide guidance on the management of portfolios, programs, and projects, integrated with DEWA business management framework and consistent across all divisions and departments within DEWA.

This approach aims at the following objectives:

1- Contributing to achieve DEWA's vision, mission and implementations of its strategic plan.

2- Introducing a unified and structured means of managing and controlling portfolios, programs, and projects in light of-and to deliver-organizational strategy across all divisions and departments within DEWA.

3- Incorporating a unified standard for project management, one standard concepts and terminologies throughout the organization.

4- Utilizing project management best practices to deliver DEWA projects in terms of scope efficiency, quality, time and budget.

5- Enrich DEWA employee's competitive capabilities in project management.

6- Providing support for DEWA PM I.REP (Register Education Provider) project management activities and maintaining License requirements.

DEWA Project Portfolio and project Management is a comprehensive view of corporate entire portfolio of projects and ability to prioritize and release programs/projects with alignment with DEWA strategic objectives. Adapt SAP best practice, International standards in PPM/PS processes.

Provide standardized platform (PMIS) for PPM/PS processes In Alignment with ISO 21500 guidance for Project Management, and PMI standards.

Standardize departmental processes within the division Better utilization of resources through Multiple Resource Scheduling (MRS).

Improve Tendering, Planning, Execution Reporting and Tracking of internal and external DEWA projects thru SAP PPM/PS Integration of the processes with Materials Management, Financial Systems, HR, and other SAP modules. KPI reports \& dashboards that supports strategic and operational decision-making. 
In order to foster increased competitiveness and sustainability, organizations are implementing projects to build their paths for the future. As such, the concept of project management has become an increasingly important subject in various business fields. According to Newton (2015), there are different ways in which projects can be approached. Various methodologies and/or frameworks have been developed in order to look at projects in their own practices. In line with this, Newton (2015) identified the key project management methodologies to include Agile, PMBOK, Six Sigma, PRINCE2, and Critical Chain. These are the most common project management methodologies that are widely used by project managers worldwide. In order to have a better understanding of the emerging topics in the project management field, these concepts are explored and linked to organizational success.

\section{Agile Concept}

Further, agile approach is one of the most common project management methodologies. As such, the agile project management (APM) can be described as the ideal model for modern and information age projects. According to Rico (2010, p. 37), “Agile Project Management (APM) is a new paradigm for managing high-risk, time-sensitive, research and development-oriented new product development projects." This means that APM is widely used for managing complex and modern projects within the constantly changing business environment. As clarified by Rico (2010), the theory of complex adaptive system suggests that modern complexities must be managed beyond the traditional management practices and principles in order to lead positive change. In other words, the cutting edge complexities must be overseen past the customary administration practices and standards, keeping in mind the end goal which is to focus on and lead positive change. This specific theory is linked to the agile PM methodology where the modern complex systems are subjected by the unstable market conditions.

As highlighted by Elliott (2008), agile project management places emphasis on throughput, teamwork and leadership. In line with this, the same author identified the different key agile principles to include:

- Focusing on customer value.

- Fostering iterative and incremental delivery.

- Provision of intense collaboration.

- Building of small and integrated teams.

- Self-organization.

- Small, continuous improvements.

In today's contemporary era, there is a need for responsiveness and agility in order to enable firms to cope with the unpredictability and changes in the global business arena. As such, the concept of agile project management was developed in order to address project complexities beyond traditional approaches. As highlighted by Cervone (2011) the agile project management approach was developed in order to emphasize two important concepts: (1) risk can be reduced by focusing on short iterations of clearly defined variables and (2) direct communication with stakeholders is emphasized in the development process in order to create effective project documentation. (Cervone 2011).

\section{Value-driven projects}

- In line with the agile project management concept, project success can also be achieved by utilizing value driven approach. This means that firms need to build value-driven relationships in consideration of the three project elements including business, project management office and project team (Faisal, Safitri and Dahlan 2013). This suggests that it is important for project managers to manage value-driven projects in order to foster project success in the rapidly changing global marketplace. As such, Faisal, Safitri and Dahlan (2013) noted that fostering valuedriven projects can promote long-term commitment, relationship and mutual benefits that can lead to project success. Thus, value-driven projects is commonly guided by the value-driven project management model suggesting that successful projects are driven by certain values of project management such as time and cost of the project, transparency, company image, customer satisfaction and cross-functional interaction among others (Polkovnikov and Ilina 2014). This suggests that value-driven projects produces user-valued features particularly 
in terms of making sound decisions so as to promote project success. As highlighted by Collier (2012), valuedriven development is about creating projects that has user-valued features that users care about and understand. Thus, value-driven projects can enhance the effectiveness and sustainability of projects that can affect their success. Figure 1 shows the framework of the value driven relationship between the three important elements of project success (the business, the project management office and the project team) and change management.

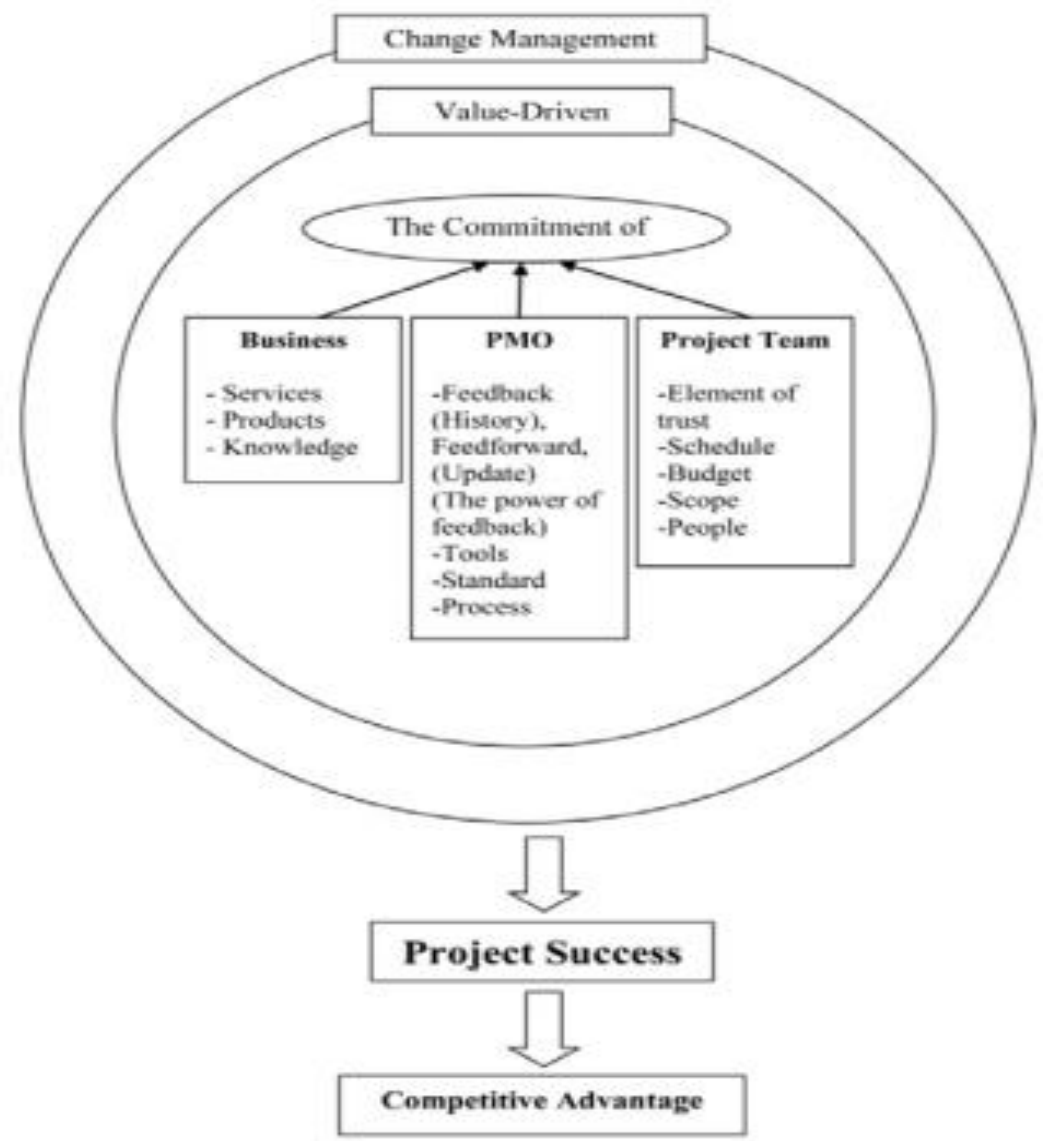

Fig. 1 Framework of Value Driven Relationship (Faisal, Safitri and Dahlan 2013)

\section{1. another five to six percent in 2015.2Structure}

\section{Managing Projects for innovation}

Moreover, the concept of managing projects for innovation has also become an important subject in the field of project management. This is due to the significant role of innovation in the sustainability of businesses in the modern world. According to The Project Management Institute (PMI) (2011), modern businesses particularly in developing economies are becoming promoters of business innovation in an effort to foster competitiveness and sustainability. As explained by the same author, modern businesses are constantly attempting to come up with new product/service developments that are cheaper, reinvent production and distribution systems and experiment on new business models so as to achieve innovation. As such, managing projects for innovation has become an important driver of competitiveness and sustainability.

In order to understand the concept of managing projects for innovation, it is important to know the different definitions and/or principles of innovation. Table 1 shows the new definitions of innovation as adapted from the Project Management Institute (2011). 


\section{Type of Innovation/ Innovation Business Models}
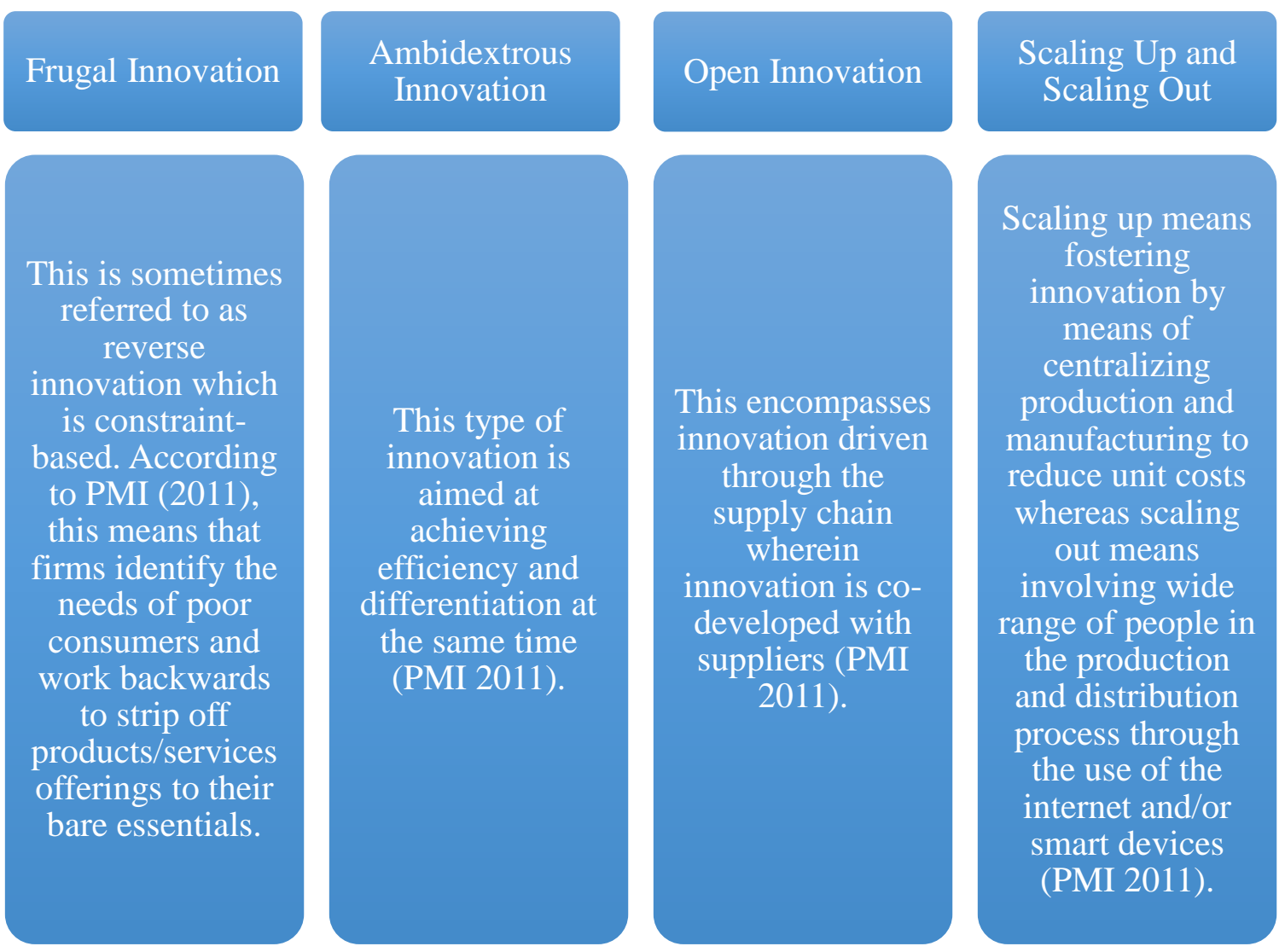

In line with the different types of innovation and innovation business models, PMI (2011) identified the different innovation areas wherein most of them involve industry convergence (shown in figure 2). According to the same author, the six innovation areas include mobile technology, mobile money, alternative energy, mobile medicine, convergent healthcare and human 2.0.

In relation to managing projects for innovation, one of the most effective tools in resource allocation is project portfolio management. It is used to enable the management to select projects with the highest potential to become new products and services winners in the future. In a study by Stadnick (2007), the author suggested that project portfolio management methodology contributes to innovation. Thus, managing projects for innovation is based on the principles of the management and innovation theories suggesting that innovation is an important aspect in firms' growth strategies particularly in project-based firms. As highlighted by Keegan and Turner (2000), managing projects for innovation is a new management paradigm in achieving project goals. This suggests that designing innovative products and services can be viewed as one of the most important capabilities of modern businesses in order to enable them to address and meet the changing and evolving customer requirements.

\section{Complexity within projects}

Therefore, in line with managing projects for innovation, it is important to understand the complexities and uncertainties within projects. According to Ameen and Jacob (2009), modernity influences project complexities particularly in relation to managerial demands due to different situations faced in project development and implementation. This is based on the complexity theory wherein it provides varied view of management particularly 
in relation to project management. As such, project complexity can be defined as "consisting of many varied interrelated parts and can be operationalized in terms of differentiation and interdependency" (Baccarini 1996 cited in Ameen and Jacob 2009, p. 6). Thus, Dombkins (2008) cited in Ameen and Jacob (2009, p. 5) noted that in lieu of the complexity theory, "complex projects have a high degree of disorder and instability" because they can be described as complex evolving systems. As highlighted by Baccarini (1996, p. 201), it is important to acknowledge the significance of complexity in project management because it can help in determining the planning, coordination and control requirements. The same author further explained that complexity within projects can hinder clear identification of objective and goals of major projects that can have profound impact on project outcomes.

As proposed by Baccarini (1996), it is important to identify the type of complexity within a project in order to determine the most appropriate project management process to be implemented in dealing with complexity. In line with this, complexity within projects can best be understood based on the different typologies of complexity.

- Complexity of Faith - this refers to complexities involved in the creation of something different or unique or solutions toward solving new problems (Ameen and Jacob 2009). Thus, this type of complexities can arise within projects due to uncertainties.

- Complexity of Fact - this refers to uncertainties in dealing with large amount of independent information (big data) (Ameen and Jacob 2009).

- Complexity of Interaction - this refers to complexities present in interfaces (i.e. ambiguity, neutrality, etc.).

- Organizational complexity - this describes differentiation in the number of hierarchical levels and/or units, and division of tasks. As explained by Ameen and Jacob (2009), differentiation has two dimensions - vertical and horizontal differentiation.

- Technological complexity - this describes complexities in the areas of operations, characteristics of materials and characteristics of knowledge (Baccarini 1996 cited in Ameen and Jacob 2009).

- Social Intricacy of Human Behaviour - this describes uncertainties in human responsiveness particularly in facing collective challenges as a team or society as a whole (Oehmen, et al 2015).

- Uncertainty of long lifecycles - this refers to the different factors increasing uncertainties to which project activities are exposed such as communication infrastructure, scale of human activity and considerations of long term lifecycles among others (Oehmen, et al 2015).

- Understanding complexity within projects is important in order to allow project managers to better ideas on how to handle complex projects and address difficulties in coping with the increasing complexity within the project management discipline.

In DEWA during the project phases of designing and civil construction, the stages might affected with the complexity of delaying such as, the drawings that can't be agreed among the stakeholders because of the wrong calculation that is determined by the concern group. Therefore, DEWA project team will conduct workshops to discuss and agree regarding any conflict may occur during the design stage. Furthermore, civil construction work, consider an essentials due to the limited number of civil contractor in the market due to increasing of economical growth in Dubai along with highly demand in civil contractions. Many of DEWA projects get delayed due to the non-availability of an appropriate civil contractor that affect the project progress in terms of delaying milestone which is affect the OBS KPI. DEWA has arranged trainings to those civil companies along with having a meeting coordination quarterly to track the project life cycle with the avidness of any further issue.

Finally, in understanding the concept of project management, it is important to consider the roles of project managers in implementing successful projects. According to Kerzner (2017), in a diverse business environment wherein project managers interact with on a daily basis, competitive edge is also very important. This is because nowadays, there are already many project managers who are equally as talented and skilled in the technical aspects of project management as the others are.

While it is undeniable that in a project management position, technical skills or hard skills are important and that in most cases, the project manager's success is being measured by the technical aspect of his job, it is also apparent that nowadays, a project manager's soft skills are also increasingly becoming more relevant and significant than it was 
before due to the changing nature of the business environment (Kerzner 2017). The project manager's soft skills are therefore considered as his competitive edge over his competitors and serves as the foundation of his effectiveness in fulfilling the functions and roles of a good project manager (Gillard 2009).

Due to the many changes in the business environment, the roles of project managers are also fast changing and the emphasis on the development and exercise of soft skills among project managers is more relevant and significant today than it was before. Nowadays, project managers are being taught the importance of honing their emotional intelligence and leadership skills in order to fulfill their job roles more effectively (Azim 2010).

In addition, the expected productivity levels of project managers are greater nowadays due to the changing and increasingly becoming competitive nature of the industries. As a result of the difficult times and complexities within projects, project managers are forced to exert more effort when it comes to exercising their leadership capabilities as the success of the company depends heavily on them (Kerzner 2017). Thus, there is no doubt that indeed, the changing nature of the business environment is what continuously pushes project managers to shift their focus from simply developing their technical skills but also enhancing their soft skills.

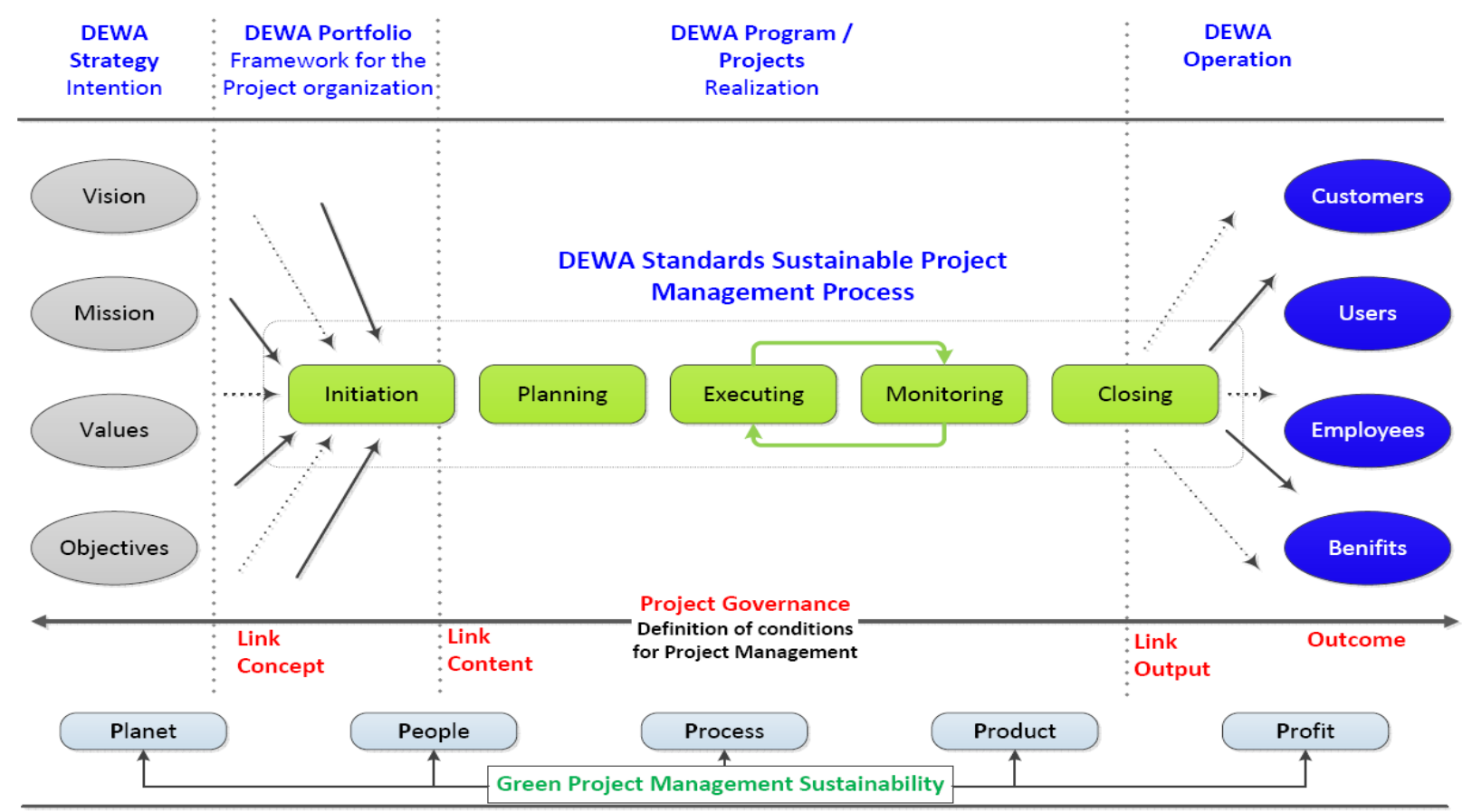

\section{The Solution}

DEWA's leadership established a dedicated team, including senior management representatives, to begin implementing SAP software for its portfolio and project management and enterprise asset management systems. DEWA launched a multi-phase implementation project that concluded at the end of 2015. The first phase began in October 2009 with a focus on customer services. Phase II followed in January 2012. It focused on procurement, stores, finance and human resources. The third and final phase comprises enterprise asset management generation, projects and portfolio management for generation, transmission and water, fleet management, business preparation and consolidation processes for the financial department, and a project system for business support projects. Initiated in March 2014 and launched in

September 2016, phase III aimed to standardize, simplify, and automate the enterprise asset anagement and portfolio project management/ project system processes. Recognizing that active participation and support of employees was a key factor in the successful implementation of the software, DEWA held educational sessions to increase awareness about the project. This would enable employees to more effectively utilize the system, thereby maximizing its benefits. 
With the software in place, DEWA is better able to supplement its existing project management efforts, including alignment of capital and operational spending, planning and budgeting, and early identification of opportunities and risks.

"SAP software provides us with integrated solutions that contribute to DEWA's objective to achieve sustainable development, especially as indicated by international best practices," said Al Tayer. "One of our goals is that our processes be world class, yet simple and easy to use."

\section{Achievements}

As a result of this implementation, DEWA is now more efficiently managing projects that support its strategic plan and the four distinct perspectives in its balanced scorecard: financial, internal processes, customers, and the support of learning and growth.

DEWA has replaced more than ten legacy systems in its finance and accounts, consumer self-services, procurement and human resources areas. Project highlights include reducing:

- The monthly closure of accounting books from 20 days to five

- Budget checking from three days to one minute

- The number of steps in the utility connection process from nine to one

- The time it takes to move purchase requisitions into the

payment cycle from 60 days to 15 In 2012, DEWA won the Bronze Quality Award from SAP for Europe, the Middle East, and Africa in the Large Implementation category. It was recognized for its use of a suite of SAP solutions to improve efficiencies throughout the organization. "This award reaffirms our leadership and our renewed drive toward more achievement and innovation," said Al Tayer.

Through DEWA's commitment to the delivery of sustainable electricity and water services at world-class levels of reliability and efficiency, and its continued appreciation of the value of project management, the United Arab Emirates, represented by DEWA, ranked first in the world for getting electricity in the World Bank's Doing Business" 2018 report.

\section{Recommendations:}

While DEWA is known for completing successful projects, it is still important to consider that there is always room for improvement. Thus, this set of recommendations are proposed for the DEWA management to further improve their existing project management activities and practices.

- In relation to managing complex projects, it is recommended for project managers to acknowledge complexities and develop managerial sensitivity toward project uncertainties in order to allow them to continuously develop solutions or revise solutions toward the identified aspects of problems. It is important that project managers don't rely on treating complexity as simple because it can only lead to chaotic projects (Oehmen, et al 2015).

- It is important for project managers to have a better understanding of complexities within projects and to be engaged as early as possible and during initiation phase. As such, it is recommended for DEWA management to invest in continuous trainings to develop skills and knowledge of project managers particularly in relation to managing complex projects. Examples of trainings include communication skills training, managing complex projects workshop and implementing technological structures program. (DEWA is a PMI R.E.P Register Education Provider for PMI Activities)

Provide project managers understand different project management methodologies and tools in order to permit them to identify issues that may arise during planning and implementation of innovation projects. This will allow project managers to have opportunities to tailor project management tools in accordance to the demands and requirements of 
the projects (Yakovleva 2014):

- Enhancing project manager skills by Incorporating innovation concepts

- Embracing changes and ability to take action.

- Digitizing and centralizing works through and enterprise management systems. PMIS (Project Management Information System Tool), in DEWA is SAP.

- Project Manager recommended to be courage and has the legitimate power to solve project issues, stakeholder's engagements and customer requirements proactively.

- Project Managers should be innovative and creative in projects.

- Project Managers should improve code of ethics and professional conducts.

- Project Managers should contribute by sharing lessons learned and best practices to all future projects.

- Project Managers to be aware of culture differences specially in multicultural organizations.

\section{Conclusion}

DEWA continues to make inroads when it comes to incorporating project management concepts and terminology throughout the organization. The SAP software enables DEWA employees to structure projects more consistently, transfer knowledge, and periodically evaluate methodologies to identify improvement opportunities - all of which leads to increased efficiencies, value, and customer satisfaction.

\section{Building the Future}

As the first organization in Dubai and the UAE to become a Registered Education Provider (R.E.P.) DEWA is well

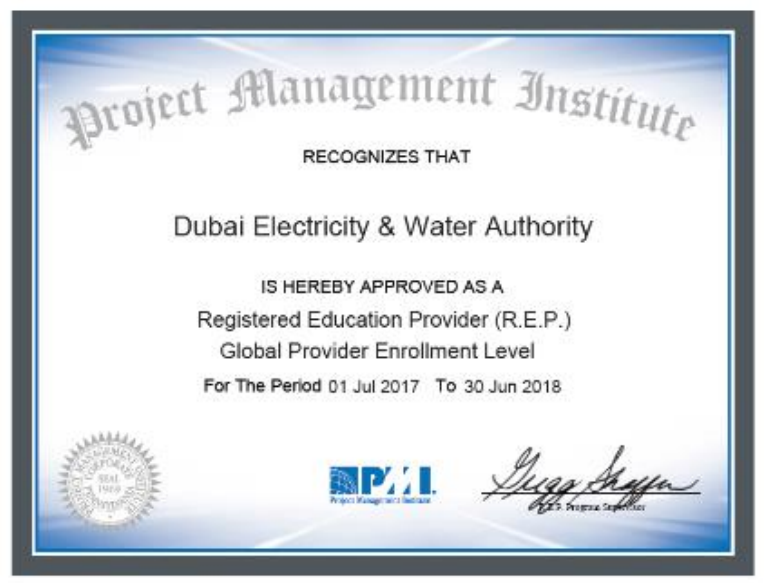

equipped to provide the appropriate educational tools to keep employees up to date with project management standards. As an R.E.P., DEWA delivers accredited courses and activities directly to its employees. This results in considerable savings. "We consider our employees the most important pillar of our success," said HE Saeed Mohammed Al Tayer, MD and CEO of DEWA. "We take priority in involving staff in all initiatives and projects."

In addition to PMI courses, DEWA collaborates with other institutions of higher learning to assist students with earning Bachelor's degrees in electrical and mechanical engineering. With an eye to helping build the future workforce for the renewable energy and sustainability sectors, DEWA launched the Renewable Sustainable Energy Program for high school graduates. As of 2017, 30 students were enrolled - 20 at the University of Sharjah and 10 studying abroad.

\section{References}

[1] Albert W. (1965). Development Planning: Lessons of Experience, pp. 249

[2] Ameen, M. and Jacob, M. (2009). Complexity in Projects, Thesis [online]. [Accessed 27 October 2017] at: https://www.divaortal.org/smash/get/diva2:158819/FULLTEXT01.pdf

[3] Albert O. H. (1967) Development Projects Observed, pp. 1.

[4] Azim, S, (2010). The importance of soft skills in complex projects. International Journal of Managing Projects in Business, Vol. 3(3), pp. 387401

[5] Baccarini, D. (1996). The Concept of Project Complexity - A Review. International Journal of Project Management, Vol. 14(4), pp. $201-204$.

Cervone, H. F. (2011). Understanding Agile Project Management Methods Using Scrum. OCLC Systems \& Services: International digital library perspectives, Vol. 27(1), pp. 18-22.

[6] Collier, K. (2012). Agile Analytics -A Value-Driven Approach to Business Intelligence and Data Warehousing, Pearson Education, Boston.

[7] Dennis A. Rondinelli. (1976). Project Identification in Economic Development. Journal of World Trade Law, Vol. 10

[8] Elliott, S. (2008). Agile Project Management [online]. [Accessed 27 October 2017] at: https://www.cs.helsinki.fi/u/paakki/Elliott.pdf

[9] Faisal, A. A., Safitri, C. and Dahlan, A. R. A. (2013). Value-Driven Approach for Project Success and Change Management in Malaysian 
[10] Institutions of Higher Learning (IHL). International Journal of Science and Research, Vol. 2(6), pp. 8-12

[11] Gillard, S. (2009). Soft Skills and Technical Expertise of Effective Project Managers. Issues in Informing Science and Information Technology, Vol. 6, pp. 1-8.

[12] Keegan, A. and Turner, J. R. (2000), The Management of Innovation in Project Based Firms, ERIM Report Series ERS-2000-57-ORG [online], [Accessed 27 October 2017] at: http://citeseerx.ist.psu.edu/viewdoc/download?doi=10.1.1.26.740\&rep=rep1\&type=pdf

[13] Kerzner, H, (2017). The Role of the Project Manager: How and Why It's Changing [online], [Accessed 27 October 2017] at: https://blog.iil.com/the-role-of-the-project-manager-how-and-why-its-changing/

[14] Newton, P. (2015). Principles of Project Management - Project Skills [online], [Accessed 27 October 2017] at: http://www.free-managementebooks.com/dldebk-pdf/fme-project-principles.pdf

[15] Oehmen, J., Thuesen, C., Parraguez, P., \& Geraldi, J. (2015). Complexity Management for Projects, Programmes, and Portfolios: An Engineering [2] Systems Perspective, PMI White Paper, Project Management Institute, PMI.

[16] Polkovnikova, A. V. and Ilina, O. N. (2014). The Reality of Project Management Practice in Russia: Study Results. Procedia - Social and Behavioral Sciences, Vol. 119, pp. 805-810.

[17] Rico, D. F. (2010). Lean and Agile Project Management: For Large Programs and Projects, Springer.

[18] Stadnick, P. (2007). Project Portfolio Management Practices for

[19] Innovation - A Case Study at ABN AMRO - Brazil, Master Thesis [online], [Accessed 27 October 2017] at: http://www.divaportal.org/smash/get/diva2:141302/FULLTEXT01.pdf

[20] United Nations. (1971). Department of Economic and Social Affairs, Administration of Development Programs and Projects: Some Major Issues, pp. 7.

[21] The PMI. (2011). Global Dynamics of Innovation and Project Management [online], Accessed 27 October 2017 at https://www.pmi.org//media/pmi/documents/public/pdf/white-papers/global-innovations

[22] Vidal, L. and Marle, F.(2008). Understanding project complexity: implications on project management.

[23] Yakovleva, A. (2014). Methodological Aspects of Project Techniques Selection for Innovation Project Management. International Journal of Innovation, Vol. 2(1), pp. 18-31.

[24] Gittinger J. P. (1972). Economic Analysis of Agricultural Projects, pp. 1.

[25] Dubai Electricity and Water Authority (DEWA) SUSTAINABILITY. REPORT 2016. DEWA AT A GLANCE. Dubai Electricity and Water Authority (DEWA), Oct 5, 2016. 